\title{
O ANJO NA ARTE CONTEMPORÂNEA. ICONOLOGIA DE UMA PRESENÇA DA AUSÊNCIA
}

\section{ANGEL IN CONTEMPORARY ART. ICONOLOGY AS REGARDS TO A PRESENCE OF THE ABSENCE}

\author{
Stefania Caliandro \\ Doutora, EHESS, Paris \\ Professora Visitante - UERJ - Rio de Janeiro
}

RESUMO: A iconologia do anjo, analisada à luz das reflexões de Walter Benjamin e de JeanFrançois Lyotard, leva-nos a investigar os efeitos de presença e a presentificação da ausência que essa figura gera nos diversos meios da criação artística.

PALAVRAS-CHAVE: Semiótica da arte; Iconologia; Estética.

ABSTRACT: The angel's iconology, in the light of Walter Benjamin and Jean-François Lyotard's reflections on this theme, leads us to analyse both the effects of presence and a presentification of the absence that this figure enables in various media of artistic creation.

KEYWORDS: Semiotics of Art; Iconology; Aesthetics.

Para Angelinho

$\mathrm{Na}$ história da arte clássica, a figura do anjo aparece freqüentemente, pois está estritamente ligada à representação do sacro. No entanto, é muito menos presente na época contemporânea, quando o "valor de culto" das imagens artísticas, sirvam-se elas de qualquer meio de expressão, cede o lugar quase por completo ao seu "valor de exibição". A distinção precisa entre estes dois "modos" conforme os quais a recepção acontece, distinção defendida por Walter Benjamin em seu famoso ensaio sobre a obra de arte, parece imediatamente atenuada pelo próprio autor, que em uma nota, após ter criticado o idealismo de Hegel, transcreve o trecho a seguir, extraído das Lições de estética, sem acrescentar mais nenhum comentário:

Não estamos mais no tempo em que se rendia um culto divino às obras de arte, onde se podia dedicar-lhes preces; a impressão que elas nos transmitem é mais discreta e a sua capacidade de emocionar ainda requer uma pedra de toque de ordem superior. (BENJAMIN, 1983, p.11-13)

Baseado nesta constatação, Benjamin articula a argumentação, tão discutida, sobre a autenticidade da obra de arte, colocada em risco pela crescente facilidade de sua reprodução técnica; ele revela uma concepção da aura própria das obras de arte, de certas 
fotografias e, até mesmo, de certos objetos "históricos" ou naturais 1 , capazes de evocar ao seu redor um imaginário individual ou coletivo. Este ponto fica provavelmente mais claro em outro texto de Benjamin, de três anos mais tarde, o ensaio "Sobre alguns temas em Baudelaire", em que o autor liga o tema da aura ao surgimento de imagens advindas da mémoire involontaire, individual ou coletiva, que elevam o objeto do anonimato das reproduções. A aura é, portanto, ao mesmo tempo, "a única aparição de uma realidade longínqua" e a "experiência" daquilo que não somente torna atual um outro lugar ou um passado (uma distância no espaço ou no tempo), mas que, na contramão do achatamento das imagens de massa e do efeito "inumano", quase "mortal", da técnica, confere ao objeto também o poder de olhar para nós, de nos obrigar a levantar o olhar².

A experiência da aura se baseia, portanto, na transferência de uma forma de reação comum na sociedade humana à relação do inanimado ou da natureza com o homem. Quem é visto, ou acredita estar sendo visto, revida o olhar. Perceber a aura de uma coisa significa investi-la do poder de revidar o olhar. ${ }^{3}$

Então, se a unicidade da obra de arte está, para Benjamin, em seu poder de atualizar o distante no aqui e no agora, de aproximar um espaço distante, assim como um tempo passado ao presente; ela encontra seu ponto máximo na imagem do Anjo da História, cujos traços Benjamin enxerga graças à aquarela Angelus Novus de Paul Klee 4 . A partir das reflexões sobre as dimensões espaciais e temporais que o anjo (e a obra de arte) encerra, sem chegar a nenhuma verdadeira mediação entre estas mesmas dimensões, proponho-me atravessar as várias formas assumidas pelo anjo na idade moderna e contemporânea, especialmente em algumas criações recentes. Este trajeto, certamente não exaustivo, antes errático e casual, vale-se também da experiência dos estudos de Daniel Arasse relativos a Anunciação na pintura; de acordo com os quais o anjo é uma figura limiar, que marca e transpõe o limite entre espaços incomensuráveis: um, humano; o outro, divino, sobrenatural, miraculoso, que o espírito humano pode perceber só em forma de dogma e - o que é mais importante para nós - do simbolismo por imagens. Então, prestaremos atenção em como o anjo é representado, na posição que ocupa no espaço, nos seus vínculos com a tradição, e também nos novos valores que lhe são atribuídos; e, finalmente, em seu nível de presença frente a um observador que levanta os olhos em sua direção. Este último aspecto, ganhando

\footnotetext{
${ }^{1}$ Para ilustrar o conceito de aura, Benjamin define estes últimos "como a única aparição de uma realidade longínqua, por mais próxima que esteja”, ibidem, p. 19.

2 À definição da aura como "a única aparição única de uma realidade longínqua, por mais próxima que ela esteja” (ibidem, p. 7), Benjamin substitui em 1939 a seguinte: "Se chamamos de aura às imagens que, sediadas na mémoire involontaire, tendem a se agrupar em torno de um objeto de percepção, então esta aura em torno do objeto corresponde à própria experiência que se cristaliza em um objeto de uso sob a forma de exercício." (BENJAMIN, [1939] 1989, p. 137.) Quanto ao inumano, Benjamin diz: "O que devia ser sentido como elemento inumano, mesmo mortal, por assim dizer, na daguerrotipia, era o olhar para dentro do aparelho (prolongadamente, aliás), já que o aparelho realmente registra a imagem do homem sem lhe devolver o olhar." Ibidem, p. 139.

3 Ibidem, p. 139-140.

4Isto não invalida o valor "a-histórico" das obras de arte no pensamento de Benjamin, conforme observa justamente Stéphane Moses (1992, p. 95-181). Moses cita uma carta de 1923 em que Benjamin escreve: "O que me preocupa é a questão da relação das obras de arte à realidade histórica. A este propósito, se há uma coisa de que tenho certeza de verdade, é que não existe história da arte [...] a obra de arte [...] é essencialmente ahistórica. [...] A historicidade específica das obras não se manifesta na "história da arte", mas em sua interpretação." (ibidem, p. 123, aqui traduzido do francês).
} 
uma força inesperada na produção artística da atualidade, leva a refletir sobre o termo inumano, ao qual gostaríamos de associá-lo, e a nos perguntar se estas obras ainda suscitam em nós impressões que pedem uma pedra de toque de ordem superior, conforme Hegel escrevia.

Embora bem menos freqüente na arte moderna e contemporânea com relação às épocas precedentes, a figura do anjo não parou de inspirar os artistas, já que permite, justifica até, utilizar-se de formas de expressão inéditas, ou então de remeter a significados novos, que lhe são atribuídos graças a seu semblante ignoto e enigmático. Nesse sentido, a arte onírica de Odilon Redon (entre outros, vejam-se L'ange et le démon e Vieil ange) e a pintura simbolista de Gustave Moreau (Jacob et l'Ange) fornecem vários exemplos: enquanto Moreau se vale dele para evocar forças sobrenaturais e animar de um exotismo espetacular a iconologia antiga que revive em seus quadros, Odilon Redon reelabora o motivo do anjo tanto para tirar realismo da representação (L'Homme ailé ou l'ange déchu, antes de 1880; L'art céleste, 1894), quanto para suspender as personagens no éter e tornar desproporcional a figura. Se não é a única forma flutuante neste espaço do sonho (Eil ballon, 1878), o anjo evoca em Redon um repertório completo de imagens sobre o art nègre e sobre os rostos daqueles povos longínquos, que reanimava os debates contemporâneos (fig. 1 Esprit gardien des eaux, 1878). Quanto a Paul Klee, autor de várias obras sobre o anjo - dentre as quais a que se refere a Benjamin, que não é, com certeza, a de melhor qualidade ${ }^{5}$, explorou o anjo (fig. 2 Der Held mit dem Flugel, 1905; Engel vom Stern, 1939; Engel voller Hoffnung) como forma espacial em que coexistem multíplices dimensões: a simbólica, a representativa, a bidimensional; não sintetizáveis entre elas, a não ser através de uma mediação instável e altamente improvável. A fisionomia, a forma e a disposição no espaço são, portanto, três dos traços que atraem o interesse dos artistas para com o motivo. A escultura de Enrst Barlach volta-se essencialmente para o último destes aspectos: o autor coloca o Anjo tremente suspenso horizontalmente (fig. 3 Der schwebende Engel, monumento aos mortos da Primeira Guerra Mundial, 1927, fundido de novo do molde em 1942), sugerindo seu vôo dessa maneira, antes que com a representação das asas. A posição dos braços, cruzados no peito, fornece por outro lado a esta fisionomia muito humana o aspecto de um morto, ou seja, de uma pessoa que acaba de morrer, evidente alusão às vítimas da Grande Guerra; só o dinamismo imobilizado no espaço e a suspensão no alto da estrutura arquitetônica conferemlhe o caráter e os poderes de um anjo. A aparência não humana, esquisita, desperta, no imaginário surrealista de Max Ernst, a representação de um Anjo do lar (fig. 4) decididamente monstruoso, fruto mais de uma exploração no inconsciente que de uma epifania divina. Igualmente, assim como Jean-Michel Basquiat destaca o momento da rebeldia do seu Anjo caído (fig. 5 Fallen Angel, 1981), Niki de Saint-Phalle empresta ao anjo a imagem de uma poderosa Nana, sexualmente feminina, excessiva, colorida e excêntrica (fig. 6 L'Ange Protecteur, 1997, na estação de Zurique, e Nana l'Ange).

O corpo híbrido do anjo, a sua função mediadora entre mundos diferentes, a sua atividade de portador de mensagens e comunicações autoritárias, são outros elementos magistralmente reinterpretados pelos grafites de Keith Haring. Sua arte carrega-se da herança iconológica do tema: faz uma paródia de seu aspecto maravilhoso, acrescentando ao tronco humano alado uma parte inferior de sereia (Sem título, 1982); recoloca em cena a função dos anjos da guarda (Sem título, 1983) ou tutelares (Sem título, 1982, pintura no encosto de uma cama); atualiza a atitude dos anjos prontos para qualquer combate (Sem título, 1982; com ao lado, o cartaz cinematográfico The Dead Zone), sua submissão a uma vontade superior (Sem

\footnotetext{
${ }^{5}$ Cfr. Claudio FRONTISI, 1996, p. 103.
} 
título, 1984); insinua as modalidades da sua expulsão e da sua queda do paraíso (fig. 7 Sem título, 1982), assim como sua origem (de um ventre quebrado como o vaso de Pandora) e sua separação em anjos do bem e anjos do mal (Sem título, 1982); moderniza, finalmente, seu poder de comunicação, equipando-o de uma mídia mais poderosa do que o simples verbo (fig. 8 Sem título, 1982; flanqueado, ironicamente, pela publicidade da revista pornográfica Penthouse, com a imagem de uma mulher angélica em êxtase). A repetição destas imagens em inúmeras variantes, e em todo tipo de material (entre outros, em barro), visa finalmente a esvaziar seu sentido e a transformar a figura do anjo em um ideograma estereotipado, que participa do todo pleno e do ruído advindo desta linguagem figurativa alucinada e desenfreada.

$\mathrm{Na}$ reelaboração do tema aparecem outras formas de espoliação e/ou de transformação iconológica. David Salle, por exemplo, representa os anjos (Angels in the Rain) como transposição pictórica de formas esculturais, desprovidas de vida. Mais drástico nesta direção, Anselm Kiefer representa e até mesmo presentifica os anjos, em seus quadros, em forma de pedras, moldadas no chumbo, cujo peso e queda gravitacional são segurados por um fio sutil (por exemplo, A ordem dos anjos, 1984-86) ${ }^{6}$. A dupla Vitaly Komar e Alexander Melamid utiliza-se dos anjos como citações no estilo clássico (Drop of Blood \& The Angel of Death, 1985-86), para reinventar e denunciar o imaginário soviético e seu aparato oficial (Family Portrait, 1978). Paula Rego, dentro de uma ótica de revisão da posição e dos valores culturalmente atribuídos à mulher, pinta diversas cenas tiradas da história da arte cristã, assim como do imaginário coletivo. Ela dá, mais especificamente, uma aparência feminina ao anjo da guarda e defensor (Anjo, 1997), e uma tez negra ou mestiça ao anjo da Anunciação (2002), que cuida de Maria também durante seu parto (fig. 9 Natividade, 2002). Na apresentação deste momento, geralmente desconsiderado na representação do sacro, ela desvela um dos tabus ideológicos que chegaram até a modernidade. No entanto, outros artistas trabalham a imagem do anjo sem acrescentar nenhuma conotação irônica ou subversiva, tratando antes de enriquecer sua arte de um senso de continuidade com a tradição. É o caso de Bill Viola, cuja obra reinterpreta diversos temas mitológicos, e que estão na base da iconologia ocidental. A instalação vídeo Cinco anjos para o milênio (Five Angels for the Millennium, 2001) consiste em uma projeção em cinco telas (respectivamente: fig. 10 Departing Angel, Angel of Birth, Angel of Fire, Ascending Angel, Angel of Creation). Estes anjos aparecem de maneira abrupta, coloridos por uma iluminação simbólica azul ou vermelha, enquadrados por tomadas que confundem o olhar do observador a respeito de sua orientação no espaço gravitacional. Flutuam na água, mergulham e emergem na superfície, de forma que o movimento, transmitido em câmara lenta, às vezes em sentido contrário, às vezes projetado de cabeça para baixo, crie a sensação de sua levitação.

O vôo, a aspiração de voar como um anjo, o desejo de encontrá-lo, a impossibilidade de um contato entre o terreno e o celestial, a queda inevitável, são outras temáticas que seduzem os artistas e os instigam a renovar o imaginário contemporâneo. Ilya Kabakov desenvolve uma série de estudos sobre como encontrar um anjo, embora este último não se deixe ver facilmente (em fig.11, How to Meet an Angel, 2000, o anjo aparece e desaparece na margem de um espaço branco), sobre como se aproximar dele, mesmo que toda tentativa de contato seja fadada a não acontecer (veja-se uma outra obra na mesma série) e, finalmente, sobre como transformar-se em um anjo (fig. 12 Wings How to make yourself

\footnotetext{
6 Anselm Kiefer é autor também da obra Papoula e memória - O Anjo da História, homenagem evidente ao texto de Benjamin, ao qual junta a menção, no título, da coletânea de poemas de Paul Celan; no entanto, esta escultura reelabora menos a figura do anjo que o imaginário determinado pela interpretação messiânica de Benjamin.
} 
better or how to become an angel, 1999). Em um trabalho de Cai Guo Qiang (fig. 13 Man, Eagle and Eye in the Sky, 2003), o flutuar no ar, ou, mais simplesmente, o ficar pairando entre o céu e a terra, o aparecer como figura - figura híbrida -, são atos suficientes para que até uma pipa possa parecer um anjo; até porque o lugar da obra encontra-se no Sahara egípcio, terra desértica, portanto propícia, segundo as Escrituras, à manifestação de criaturas divinas. As máquinas e os dispositivos complexos de Panamarenko, fruto de um gênio ainda artesanal, leonardesco, intrinsecamente fadado a permanecer no estado de projeto (fig. $14 \mathrm{Brasil}$, 2004; Catapulta; Mochila; 2005), expressam tanto a ambição de igualar o vôo do anjo, quanto a impossibilidade de desancorar o corpo humano de sua laboriosidade terrena. Projeto parecido é uma obra de Studio Azzurro, cujo título já é significativo: $O$ sopro do anjo, primeiro naufrágio do pensamento (fig. 15 Il soffio dell'angelo, primo naufragio del pensiero, 1997). Em paraquedas suspensos de cabeça para baixo no teto da arquitetura, são projetadas imagens em vídeo de personagens reconhecíveis como anjos por causa dos atributos que lhes são associados (escada, cruz). Animados por um sistema de fotocélulas que destacam os movimentos no chão, estes anjos se relacionam com os deslocamentos do público, embora fiquem em um espaço à parte, intermediário entre o alto e o baixo. Além disso, durante o vernissage a instalação foi completada pela performance de um dos autores: ele descia do céu como um anjo caído; logo, precisava de um paraquedas - emblema de sua natureza, no fundo, já humana.

Este último ponto nos leva de volta ao problema que tínhamos no começo: como é que uma obra - mais especificamente uma obra representando um anjo, ou seja, uma imagem com aparência genericamente humana, mas que remete para o registro do não representável, do não humano -, pode atualizar-se frente a um observador que olha para ela; em outros termos, como é que a representação de um anjo pode torná-lo presente, ao ponto de nos obrigar a levantar os olhos em sua direção. Trata-se da questão da presença, estudada com afinco por Herman Parret em seu ensaio Épiphanie de la présence ${ }^{7}$. Conforme o autor diz, "é presente aquilo que está lá, in vivo, hic et nunc" (PARRET, 2006, p. 7); mas esta definição torna-se mais complexa quando a presença é "nutrida de ausência", através do tempo, por exemplo, como na «lembrança »; ou mediante um deslocamento da percepção do sensível, como no caso da "alucinação", do "sonho" até à "fantasia" quando, caso extremo, "o vivido não é assumido"8 (ibidem, p. 16 e seguintes). De fato, a presença não corresponde à existência, mesmo que a ocorrência desta constitua "o núcleo consistente [le noyau dur]" da primeira (ibidem, p. 8). "O reconhecimento ou a apreensão [saisissement] de uma 'presença' esclarece Parret - é uma coisa extremamente afetiva, erótica até" (ibidem, p. 7). Proponhome então a explorar este aspecto, a partir de algumas esculturas em que, geralmente, o efeito de presença é materialmente mais importante. A escultura é, de fato, uma das artes que mais facilmente compartilha suas próprias dimensões espaciais com as do observador. Ao longo da história, esta característica, junto com seus atrativos atípicos, levou à oposição com a imagem pictórica, pois achava-se que a escultura, diferente da aparência ilusionista da pintura, deixava emergir a verdade das coisas ${ }^{9}$. A análise de obras recentes permite, todavia, compreender que, mais que com a verdade, ou, melhor, com efeitos de real, lidamos nós com diferentes "níveis de presença" (PARRET, 2006, p. 8), que contribuem a redefinir os modos da recepção, objeto da reflexão de Benjamin.

\footnotetext{
${ }^{7}$ Herman PARRET, 2006 (os trechos extraídos do original em francês são aqui vertidos ao português).

${ }^{8}$ Este aspecto se aproxima da the suspension of disbelief (a suspensão da incredulidade) teorizada para o gênero fantástico, na literatura e em outros campos.

${ }^{9}$ Cfr. Herman Parret, [2007].
} 
A escultura Anjo do Norte (fig. 16 Angel of the North, 1998), de altura dez vezes maior que a de um ser humano - ou seja, vinte metros -, tendo uma abertura alar, digamos, comparável àquela de um jumbo jet, foi concebida pelo britânico Antony Gormley para a cidade de Gateshead ${ }^{10}$. Recortando-se no panorama do centro urbano, sua figura atrai a atenção dos usuários da rodovia que fica próxima dali. Sua inserção neste sítio é apreciada seja pelos residentes, seja pelos viajantes, pois ela dialoga com o ambiente circunstante estabelecendo um valor identificatório. De alguma forma, gera o shift entre aquilo que Marc Augé (1992) define como um não lugar (non-lieu) - o espaço despersonalizado, aquele da paisagem; ou, mais, do viajante que a atravessa -, e o lugar entendido como espaço habitado, definido por seu valor antropológico. Mas acontece que este shift age de maneira bastante ambivalente. Primeiro, porque, pelas suas dimensões e sua aparência - metade homem, metade avião -, este anjo, situado entre a terra e o céu, é percebido tanto no momento de sua elevação em cima de um morro, quanto em seu aerodinamismo ancorado ao solo. Mas o que mais confere ao Anjo do Norte um efeito de oximoro é sem dúvida a figuração reduzida ao mínimo. De fato, se a recepção favorável da população urbana confere-lhe um valor identificatório, transformando-o assim em um símbolo do lugar, sua fisionomia não detalhada, sua iconicidade quase abstrata (uma pessoa média qualquer, seja homem, seja mulher) fornecem uma imagem anônima e, portanto, acolhedora quanto à projeção empática. Este anonimato, típico do trabalho de Gormley, parece contrastar o procedimento por meio do qual o artista cria suas obras, geralmente a partir de um molde humano, mais freqüentemente o seu próprio corpo. Logo em seguida, ao molde humano Gormley faz corresponder um processo de abstração que torna impossível, de fato, a percepção da origem. Este procedimento duplo, já trabalhado com muito sucesso pelo escultor pop George Segal, facilita, por um lado, o transferimento afetivo do observador para a obra contemplada; por outro, a introjeção nele da atitude personificada, e, ao mesmo tempo, generalizada, da obra. No entanto, é oportuno reparar o duplo percurso de alienação e de identificação de si, simultaneamente de humanização e de desumanização do inanimado.

O confronto com um outro Anjo, aquele quase hiper-realista de Ron Mueck, ajuda a captar as diferenças, mesmo que somente pelas dimensões e pelo tratamento do tema (fig. 17 Angel, 1997, 110 x 87 x $81 \mathrm{~cm}$ ). Simulando a representação humana até a perfeição, Meuck desmente seu próprio ilusionismo, ampliando ou reduzindo, como neste caso, o tamanho de suas esculturas. A desproporção entre o observador e o observado recoloca decididamente em causa o relacionamento empático, de familiarização e estranhamento com a obra. Devido à iconicidade fisionômica levada ao extremo, suas obras assumem expressões faciais e posturas falantes, provocando a reação emotiva do público. No caso de Anjo, o rosto envelhecido chama menos a atenção pela iconologia inusual (o anjo idoso pertence bem ao repertório tradicional), que pelo contraste entre sua presença realística e sua suspensão fora do tempo, sua ausentificação em um presente eterno; de onde vem o efeito irônico e insuportável ao mesmo tempo de sua expressão aborrecida, cristalizada para sempre.

Ao contrário, o Anjo do Norte de Gormley mostra-se como uma presença que se abstrai do contingente: não se eterniza em um fora do tempo, mas parece elevar-se dos pequenos instantes do cotidiano. Embora se coloque, como toda obra, dentro do tempo e da evolução histórica (as asas em forma de avião o atestam), seu distanciamento ascético e sua espoliação figurativa ascendem a um modelo de intemporalidade. Por este motivo as esculturas de Gormley, repetindo em lugares e situações diferentes o mesmo tipo de figura ( $A$

${ }^{10}$ Cfr. o site online do artista, www.antonygormley.com (consultado em 26 de maio de 2007) e o artigo de Cole MORETON, 2007. 
case for an Angel II, 1990), bem se adaptam aos diversos contextos e se prestam para abrigar novos significados. Do outro, intui-se bem o aspecto "inumano" - conforme afirmava Benjamin falando do daguerreótipo ${ }^{11}$ - destas esculturas, que não somente imobilizam (imobilizam-se e imobilizam o observador por empatia) no tempo e no espaço, mas não devolvem ao homem sequer o seu olhar. O rigor, por vezes insustentável, destas presenças desfiguradas de toda peculiaridade, transmite ainda uma impressão de grande solidão ${ }^{12}$.

Um outro trabalho, de recepção bastante controversa, repropõe uma presença nutrida pela ausência. O Anjo (fig. 18 Angel) de Marc Quinn, exposto, entre outros lugares, na Catedral de Winchester, na Inglaterra, baseia-se no modelo médico de um feto na vigésima segunda semana de gestação. A escultura reproduz seu esqueleto, de joelhos, com as mãos juntas e levantadas, representando o ato de rezar. Embora não se trate neste caso de um molde tomado ao vivo, esta reconstrução provocou reações éticas muito fortes, no que diz respeito à privação ou ausência da vida no estado pré-natal. Algumas pessoas viram nela uma intencionalidade laica por parte do artista, que desta forma escandalizaria e dessacralizaria o lugar em que a obra foi exposta; outras pessoas, ao contrário, justamente devido à colocação em uma igreja, fazem dela um manifesto contra o aborto, ou, pelo menos, contra a interrupção da gravidez em estádio avançado ${ }^{13}$. Não importa; o que é interessante nesta escultura é a associação da imagem à figura do anjo, não por meio de seus atributos tradicionais (como as asas), nem pelas suas conotações metafóricas (a inocência, a candura), embora elas contribuam para a sua interpretação simbólica (como vítima, por exemplo); mas porque, como o anjo, este feto não é humano, pelo menos ainda não, apesar de ele sugerir caracteres e valores de todo humanos. Se a imagem pode chocar por sua desumanidade, não se trata, todavia, nem de uma representação de uma pessoa viva, nem de uma representação do inanimado: "um modelo anônimo", como o define o autor ${ }^{14}$. Embora o esqueleto esteja colocado no ato de rezar, não adquire propriamente uma aparência humana por causa desta ação. Se parece representar o humano, isto acontece paradoxalmente graças ao seu não estar morto, ou seja, pela referência à morte que o atravessa inteiramente ${ }^{15}$, malgrado a dificuldade de falar em morte para quem nunca nasceu.

Para esta presentificação nutrida de possíveis ausências, a escultura elabora o seu potencial de vincular o aqui e o agora da recepção a outros espaços, topologicamente distantes ou imaginários, ou seja, simbólicos, e a dimensões afastadas no tempo. Os efeitos de realismo e de rebaixamento do limiar de iconicidade contribuem para enriquecer o jogo da identificação ou do estranhamento que a representação personificada envolve. A possibilidade de mostrar-se in presentia encontra-se procrastinada em uma camada espacial quando, ao contrário, o objeto é representado em uma superfície bidimensional. Este último fator, que parece antes remeter a uma tela de projeção - no caso, por exemplo, do simbolismo por imagens, da projeção onírica (o écran du rêve), ou até mesmo da aparição icônica - inscreve mais suas outras potencialidades sensoriais (táteis, cinestésicas, etc.) sob a égide da visão. Todavia, um outro fenômeno de presença intervém quando, por gênese material, a obra tece uma ligação com a presença passada do ter estado lá do objeto. Trata-se de uma presença

\footnotetext{
11 Cfr. nota 3 supra.

${ }^{12}$ Esta impressão ao mesmo tempo de anonimato e de solidão, apesar do número, parece estar ligada aos nãolugares, estes espaços de viagem ou de transição descritos por Augé, em que os indivíduos não são nem identificados, nem localizados, e menos ainda levados a se socializar. Cfr. AUGÉ, 1992, p. 139, 147 e seguintes. ${ }^{13}$ Cfr. Sara NEWMAN e Arifa AKBAR, 2007; Dominic LAWSON, 2007; Michael ARCHER, 2007.

${ }^{14}$ Marc Quinn citado por Jean Claude VANTROYEN, 2007.

${ }^{15}$ Quero ressaltar um forte efeito de oxímoro nesta obra de Marc Quinn, que junta a imagem do anjo-criança e a figura do anjo da morte, frequentemente representada na tradição iconológica como um esqueleto adulto.
} 
transposta no tempo manifestada pela fotografia, por seu aspecto de documento, assim como ocorre pelo molde na escultura (e, em versão reduzida, no retrato pintado a partir do contorno da sombra). Este momento de presença procrastinada no tempo - nunca certa, obviamente, se considerarmos as diversas manipulações possíveis -, encorajava Benjamin a falar em aura também no caso do retrato fotográfico, quando relegava este meio em geral ao nível de simples reprodução técnica. Igualmente, o mesmo momento de presença do passado sugeria a Roland Barthes a reflexão sobre o ter estado lá na fotografia, signo de uma ausência atualizada pela recepção. Parece-me, então, legítimo distinguir diferentes configurações da presença geradas pelas potencialidades (espaciais, temporais, icônicas) do meio, e, dentro destas configurações, multíplices níveis de presença dependendo de sua ativação nas obras.

Vejamos rapidamente como os artistas têm brincado com esta outra forma de presentificação ao fotografar anjos. Sem considerar Isolde Ohlbaum, cujas fotos testemunham o repertório de anjos esculpidos em tumbas e monumentos ${ }^{16}$, os artistas tiveram que repensar o problema da aderência ao real fotográfico para tratar deste tema. Alguns, como Yves Klein, recorreram exatamente ao efeito de real para consagrar como verdade uma percepção diferente. Em $O$ salto no vazio (fig. 19 Le saut dans le vide, 1960), Klein se faz fotografar em posição de queda aparente de um edifício, como para comprovar seus poderes de transcendência espiritual. Outros, como Édouard Boubat (fig. 2015 août 1958), documentaram o disfarce em anjo, último avatar de uma tradição vulgarizada desta figura. Entre estes dois pólos, o trabalho de Duane Michals se vale das possibilidades técnicas (especialmente a dupla exposição) para recriar imagens do sobrenatural, espirituais ou de fantasmas. Contudo, na sequência fotográfica Anjo caído (Fallen Angel), o artista põe em cena uma figura mascarada de anjo para contar simbolicamente a queda deste, depois de realizado o desejo sensorial. Com a intermediação técnica brincam as fotos de Jerry Uelsmann (fig. 21-22), em que fíguras híbridas, parecidas com a do anjo, resultam da manipulação de inúmeras fotos em câmara obscura, ainda antes da afirmação do digital. Parecidas no espírito, afastando, no entanto, todo propósito ilusionista em favor da emergência de uma sugestão poética, são as fotos retocadas de Robert e Shana Parke Harrison (fig. 23-24).

Poéticas mas também livres de disfarce e de retoques, para revestir-se de um valor simbólico fortemente evocador, as fotos de Francesca Woodman recolocam em questão, de maneira muito original, a relação entre o representado e o vivido. Na série sobre o anjo (fig. 25-26 From Angel Series, 1977-78), ela fotografa-se ou fotografa uma amiga, seu modelo favorito - trabalho sobre o narcisismo assim como sobre o duplo de $\mathrm{si}^{17}-$, em posições e atitudes que se referem ao anjo. Também em fotos que não pertencem a esta série, um pequeno gesto, aparentemente, a abertura dos braços, como podemos ver, por exemplo, na figura. 27, é suficiente para evocar este tema, quase onipresente em suas imagens (entre outras, Untitled (Black Cape), 1976-77); igualmente, o corpo agachado, revestido nos ombros de papel rasgado, lembra a figura híbrida do anjo, entre a pureza e a sujeira do informe, entre a elevação de seu espírito e a abjeção de sua aparência encarnada (fig. 28 That at one point I did not need to translate the notes; they went directly to my hands, 1976). Outras fotos podem ser relacionadas a um certo fetichismo angélico; mas, sem dúvidas, a série Sobre ser um anjo (fig. 29 On being an Angel, 1977, com um ponto de vista mais que do vôo de um pássaro, quase do vôo de um anjo, que ainda brinca com a identificação e despersonalização do sujeito) reelabora os termos de pureza idealizada e sensualidade carnal, até o grito da queda

\footnotetext{
${ }^{16}$ Esta fotógrafa realizou uma coletânea de imagens do tema, cfr. Isolde OHLBAUM, 2007.

${ }^{17}$ Sloan Rankin-Keck, amiga do primeiro ano de república na Rhode Island School of Design, foi uma colaboradora fiel e modelo em muitas fotos de Francesca Woodman. Woodman divertia-se a dificultar o reconhecimento do corpo da amiga com a imagem de seu próprio semblante em auto-retrato.
} 
abrupta no mundano (fig. 30 outra foto da mesma série), da mancha da sujeira humana no corpo, ao abandono do mito angélico autoconstruído. O simbolismo figurado e a realidade vivida por Francesca Woodman parecem fundir-se a tal ponto nestas imagens, que o suicídio da artista, que se jogou pela janela de sua residência aos vinte e dois anos de idade ${ }^{18}$, prolonga e acresce o sentido de sua obra, quase como se a inumanidade do anjo sucumbisse e, ao mesmo tempo, sobrevivesse, graças às fotos, ao seu ser demasiado humano.

Eis, portanto, em que sentido, a meu ver, as obras estimulam dentro de nós - e, até, nos impõem -, uma reflexão que ultrapassa o evento de seu encontro; nos obrigam, por assim dizer, a uma parada no tempo para que nos deixemos invadir por uma percepção de ordem superior. Que ela concirna menos ao religioso que ao ético, ao existencial ou a outros valores, não significa que este retorno ao humano não exija uma sensibilidade afinada, uma pedra de toque mais elevada. A figura do anjo, emblema da arte com a sua aura, garante também, então, na época contemporânea, uma epifania; mas esta epifania tornou-se uma profundidade escancarada, um momento de béance no invisível, uma "presentificação [mise en présence] do fato da ausência"19. Mais que um valor de culto, o anjo é o lugar, na acepção de Jean-François Lyotard, de uma "apresentação negativa", que desencadeia os terrores ligados às privações: terror da solidão, terror do vazio, terror da morte $[\ldots]^{20}$. Mas este "paradoxo de uma apresentação que não apresentaria nada", explica porque $\mathbf{O}$ inumano gera, segundo Lyotard, divagações [causeries] a propósito do tempo ${ }^{21}$. Como no aqui e agora da aparição inumana do anjo, fosse ele um desconhecido humanizado, "a presença é o instante que interrompe o caos da história e lembra, ou diz, apenas, que "há" [ 'il y $a$ '] antes de qualquer significado daquilo que há" ${ }^{22}$. Coloca-nos frente ao lugar e ao tempo presentes, assim como a seu potencial de ausências. Está nisso a força da arte que nos impulsiona a darlhe senso, a procurar significados que nos concernem e que olham para nós. Ora, se este fenômeno não acontece para toda criação estética, é porque, finalmente, somente as obras que nos tocam têm o poder de nos abrir para as nossas próprias profundidades.

\footnotetext{
${ }^{18}$ Cfr. Peggy PHELAN, 2002.

${ }^{19}$ Herman Parret (2007, p. 44) usa esta expressão conforme faz Gérard Sfez (Jean-François Lyotard. La faculté d'une phrase, Paris, Galillée, 2000, p. 33-34), para distinguir a relação do invisível com o visível na concepção de Lyotard com relação à de Merleau-Ponty.

${ }^{20}$ LYOTARD, [1988a, p. 110 do original] 1989a, p. 103. Retomando e criticando Kant a propósito do sublime, Lyotard (ibidem, [p. 110-111] trad. portuguesa. p. 104) afirma:
}

Kant despoja a estética de Burke do que penso ser o seu maior desafio: mostrar que o sublime è provocado pela ameaça de nada ocorrer. O belo dá um prazer positivo. Existe, porém, outro tipo de prazer ligado a uma paixão mais forte do que a satisfação, que é dor e a aproximação da morte. [...] No léxico de Burke, esta paixão extremamente espiritual chama-se terror. Ora, os terrores estão ligados a privações: privação da luz, terror das trevas; privação do outro, terror da solidão; privação da linguagem, terror do silêncio; privação dos objetos, terror do vazio; privação da vida, terror da morte. O que é assustador, é que o ocorrerá não ocorra, cesse de ocorrer.

Para que este terror se misture com o prazer e componha com ele o sentimento sublime, é ainda necessário, escreve Burke, que a ameaça que o engendra seja suspendida, mantida a uma certa distância, retida.

${ }^{21}$ LYOTARD, [1988b, p. 96 do original] 1989 b p. 91 . A tradução do subtítulo do livro, porém, não dá conta do original.

22 Ibidem, [p. 97] trad. portuguesa p. 93. 
CASA, Vol.7 n.2, dezembro de 2009

\section{Referências Bibliográficas}

ARCHER, Michael. Losing faith in church art. The Gardian Unlimited. Manchester, 3 de maio de 2007. Disponível no site www.guardian.co.uk (consultado em 31 de julho de 2009).

AUGÉ, Marc. Non-lieux. Introduction à une anthropologie de la surmodernité. Paris, Seuil, 1992.

BENJAMIN, Walter. Das Kunstwerk in Zeitalter seiner technischen Reprodizierbarkeit [segunda versão, 1936, revisto em 1939]. In: BENJAMIN, Walter. Illuminationem. Frankfurt am Main, Suhrkamp Verlag, 1961, p.148-184. Trad. portuguesa: A obra de arte na época de suas técnicas de reprodução. In: (sem organizador). Textos escolhidos. Walter Benjamin, Max Horkheimer, Theodor W. Adorno, Jürgen Habermas. Traduções de José Lino Grünnewald et al., São Paulo, Abril Cultural, 2. ed., 1983, p. 3-28.

BENJAMIN, Walter. Sobre Alguns Temas em Baudelaire, [1939]. In: Walter Benjamin. Obras escolhidas III. Charles Baudelaire: um lírico no auge do capitalismo. São Paulo, Editora brasiliense, 1989, p. 103-149.

FRONTISI, Claudio. Paul Klee: angélisme et histoire. In: Harry Bellet (org.), Face à l'Histoire. 1933-1996. Catálogo da amostra, Paris, Centro Georges Pompidou, 1996, p. 100105.

LAWSON, Dominic, Dominic Lawson: If more doctors are refusing to carry out abortions, it is for good moral reasons. The Indipendent, 4 de maio de 2007. Disponível no site www.independent.co.uk (consultado em 31 de julho de 2009).

LYOTARD, Jean-François. Le sublime et l'avant-garde. L'inhumain. Causeries sur le temps. Paris, Galilée, 1988 (1988a), p. 101-118. Trad. portuguesa: O sublime e vanguarda, O inumano. Considerações sobre o tempo, Lisboa, Editorial Estampa, 1989 (1989a), p. 95111.

LYOTARD, Jean-François. L'instant, Newman. L'inhumain. Causeries sur le temps. Paris, Galilée, 1988 (1988b), p. 89-99. Trad. portuguesa: O instante. Newman. O inumano. Considerações sobre o tempo. Lisboa, Editorial Estampa, 1989 (1989b), p. 85-94.

MORETON, Cole, City of Angels: Antony Gormley leads artists on to the streets. The Indipendent. 13 de maio de 2007. Disponível no site www.independent.co.uk (consultado em 31 de julho de 2009).

MOSES, Stéphane. L'Ange de l'Histoire. Rosenzweig, Benjamin, Scholem. Paris, Seuil, 1992.

NEWMAN, Sara, e AKBAR, Arifa. The Mighty Quinn: Art and agnosticism. The Indipendent. 3 de maio de 2007, disponível no site www.independent.co.uk (consultado em 31 de julho de 2009).

OHLBAUM, Isolde. Anges. Un lien avec l'éternité. Paris, Éditions de la Martinière, 2007.

PARRET, Herman. Épiphanies de la Présence. Essais sémio-esthétiques. Limoges, Presses Universitaires de Limoges, 2006.

PARRET, Herman. L'occhio che accarezza. Pigmalione e l'esperienza estetica. Texto divulgativo da palestra apresentada na Universidade La Sapienza, Roma, 19 de março de 2007 (texto enviado pelo autor).

PHELAN, Peggy, Francesca Woodman's Photography: Death and the Image One More Time. Signs. Journal of Women in Culture and Society. 27, 4, The University of Chicago Press, 2002, p. 979-1004. 
VANTROYEN, Jean Claude. L'ange mort dans la cathédrale. Le Soir. 8 de maio de 2007, Bruxelas. Disponível no site www.lesoir.be (consultado em 26 de maio de 2007)

\section{ANEXOS}

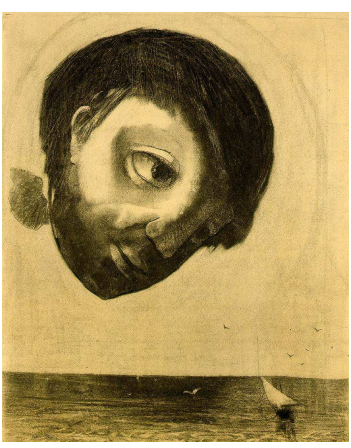

Fig. 1

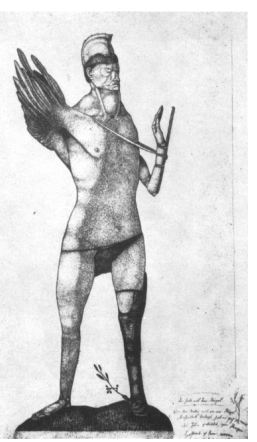

Fig. 2

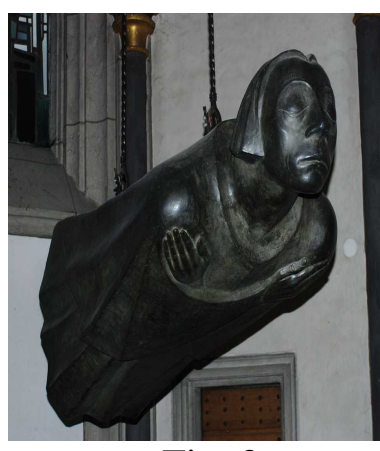

Fig. 3

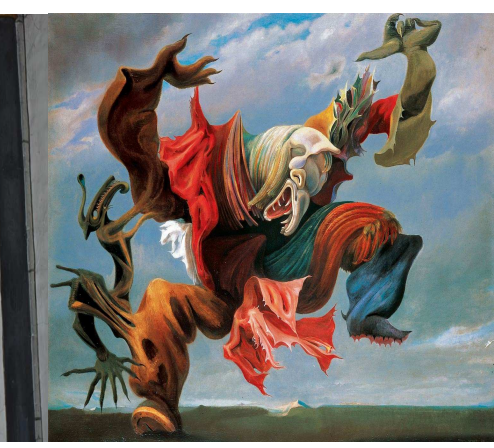

Fig. 4

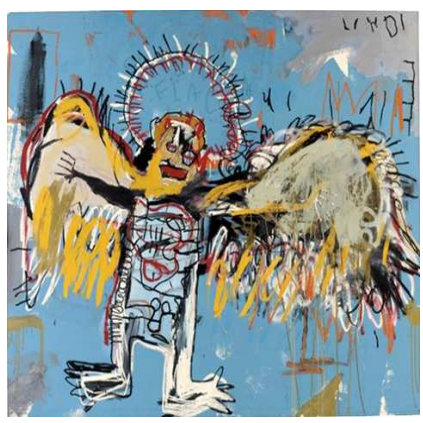

Fig. 5

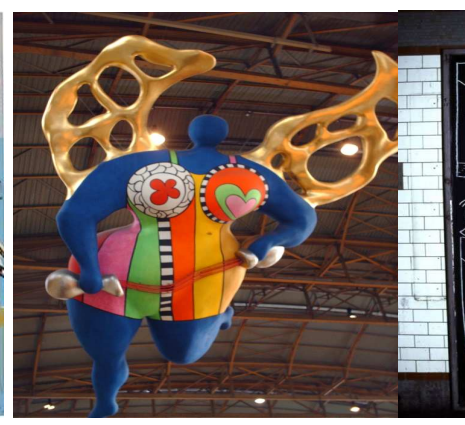

Fig. 6

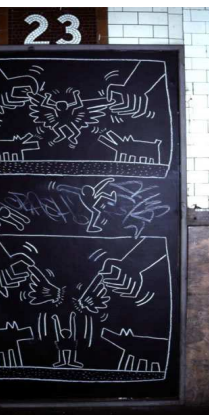

Fig.7

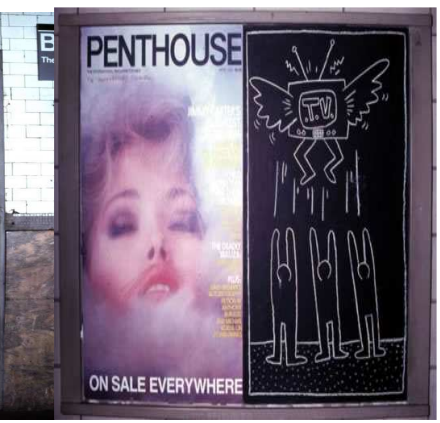

Fig. 8

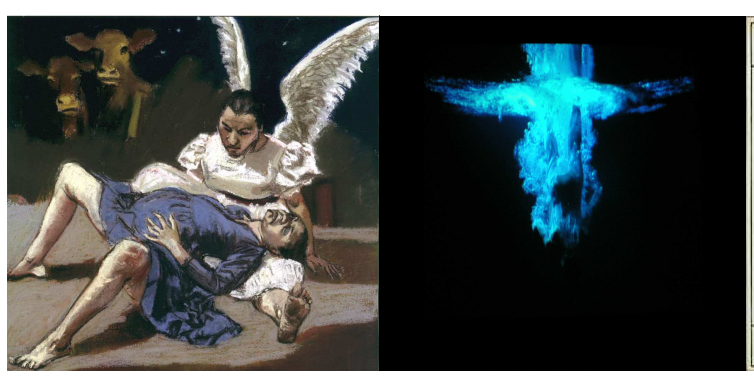

Fig. 9

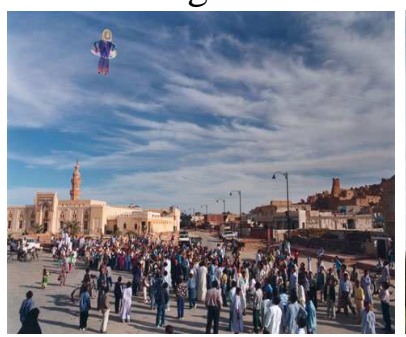

Fig.13
Fig.10

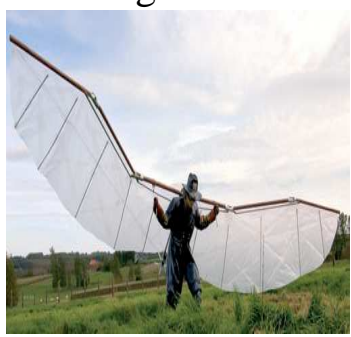

Fig. 14

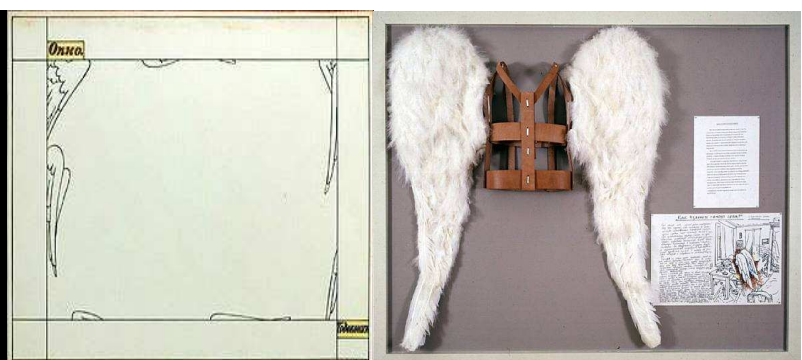

Fig. 11

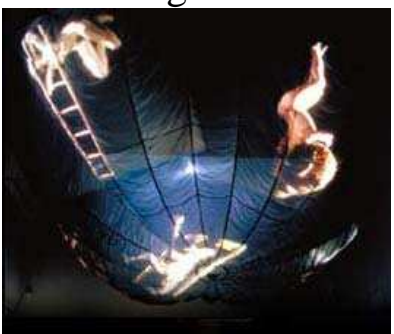

Fig. 15
Fig. 12

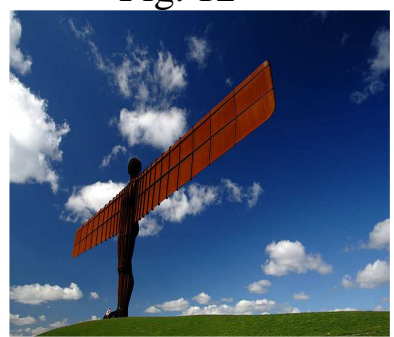

Fig. 16 
CASA, Vol.7 n.2, dezembro de 2009

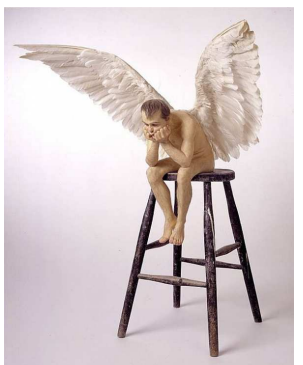

Fig. 17

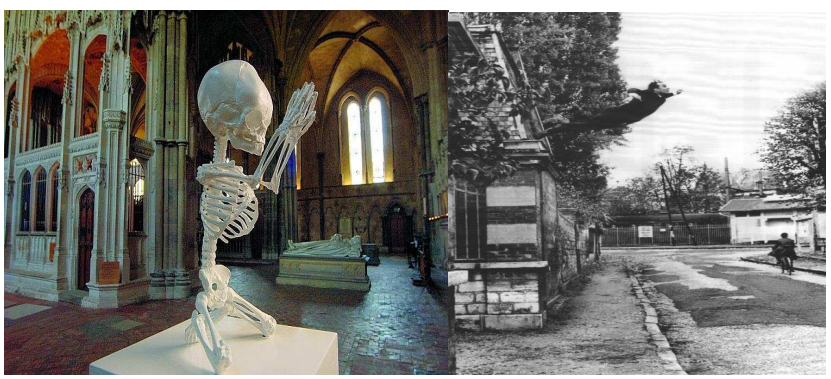

Fig. 18

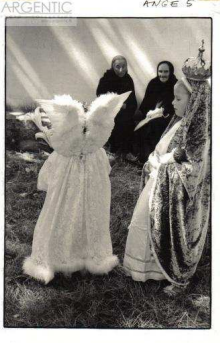

Fig. 20

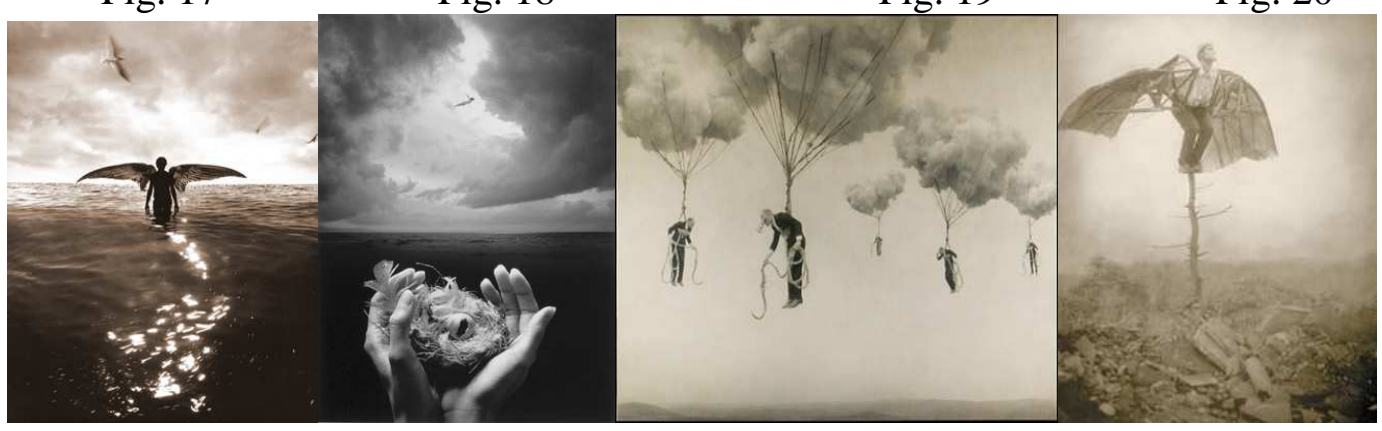

Fig. 21

Fig. 22

Fig. 23

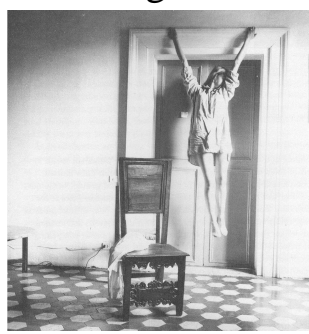

Fig. 25

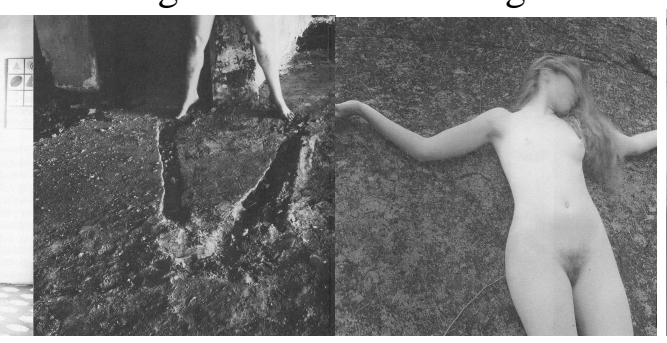

Fig. 26

Fig. 27

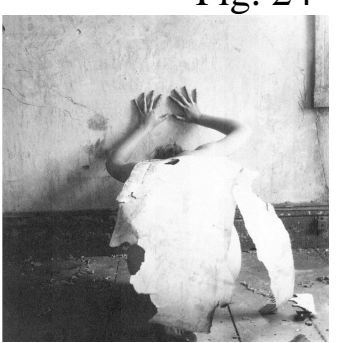

Fig. 28

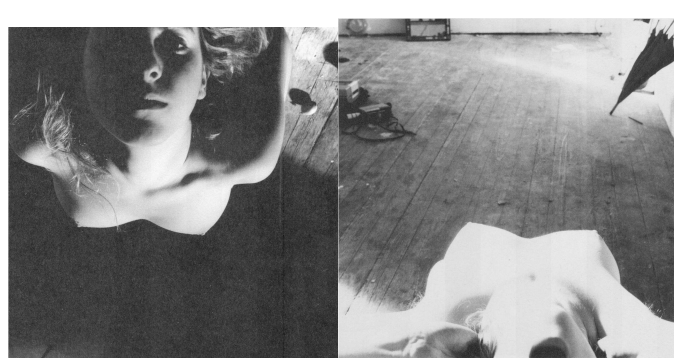

Fig. 29

Fig. 30 